\title{
Rapid column experiments to study replacement of exchangeable cations in soil samples
}

\author{
S. EL GUINDY ${ }^{1} \&$ J. HARMSEN ${ }^{2}$ \\ ${ }^{1}$ Drainage Research Institute, 13 Giza Street, Giza, Egypt \\ 2 The Winand Staring Centre for Integrated Land, Soil and Water Research, P.O. Box 125, \\ NL 6700 AC Wageningen, Netherlands
}

Received 16 November 1988; accepted 11 April 1989

\begin{abstract}
A new and rapid soil column technique is described that can be used to verify model calculations on transport and exchange of cations in soil. For this technique equipment for high-performance liquid chromatography (HPLC) is used. Breakthrough curves of cations are presented and compared with results of a model that simulates transport and exchange processes in a soil column. Thanks to the small column dimensions and the high flow rate, leaching of individual columns is completed within one day. Equilibrium is established almost instantaneously between the leaching solution and the soil in the column.
\end{abstract}

Keywords: column, cations, exchange, modelling, soil

\section{Introduction}

Reuse of drainage water for irrigation purposes in Egypt has become an official strategy in order to supply part of the newly reclaimed land with water. For successful reuse, the effect on soils of the salt present in the drainage water has to be evaluated. For this purpose a mathematical model, predicting the exchange between the cations of the cation exchange complex and the cations in the drainage water by use of a certain irrigation water quality, is desirable. A model may be tested with field experiments, but one is never sure that all aspects of the model are correct. With column experiments it is possible to test certain aspects. This paper deals with column experiments for testing the modelling of transport and exchange processes in the saturated zone of a homogeneous soil.

Soil column experiments have been performed with relatively large columns containing the soil material under investigation (lengths $30-200 \mathrm{~cm}$ and diameters $6-20$ $\mathrm{cm}$ ). These soil column experiments have several drawbacks. They are time-consuming (an experiment may take weeks to months) and it is difficult or impossible to use heavy soils as found in Egypt because too much pressure is necessary to pump water through the soil. To overcome the first drawback, any faster technique can be used because exchange processes are not time-dependent. Only the diffusion to the 
exchange sites can be limiting, but not when the exchangeable sodium percentage is low, as in the present experiments. With high sodium percentages, diffusion can be time-dependent because of closing of narrow pores (Blackmore, 1976).

HPLC (high-performance liquid chromatography) instrumentation appears to be useful to overcome the second drawback because column materials with small dimensions are used, which can resist a pressure of hundreds of atmospheres. With the HPLC equipment it is possible to perform fast experiments with a constant flow of the leaching solution at a high pressure.

The present paper describes the results of exchange processes that occur in a soil sample from the Nile delta in Egypt with this small soil column technique. The results are compared with formulations used in a soil transport/exchange model.

\section{Materials and methods}

\section{Experimental}

The soil sample investigated was silty clay from Zagazig Governerate at the Nile delta (Egypt). The soil sample was characteristic for the upper $30 \mathrm{~cm}$ below surface level. The CEC (cation exchange capacity) of the sample was $0.56 \mathrm{~mol}(\mathrm{e}) \mathrm{kg}^{-1}$, the $\mathrm{pH} 7.8$ and the organic carbon content $<1 \%$. Table 1 shows the particle size distribution. Fig. 1 shows the experimental set-up of the present column experiments. The column $(0.46 \times 25 \mathrm{~cm})$ is packed with the silty clay prepared as described below. The present sample, containing a high amount of clay particles, will still cause the column to clog. Therefore, the soil was mixed with acid-washed quartz sand in a ratio of $1: 2$. This mixing has only a diluting effect because we found that the CEC of this sand can be ignored $\left(<0.01 \mathrm{~mol}(\mathrm{e}) \mathrm{kg}^{-1}\right)$. During packing, the stainless steel column (with Valco fittings) was connected with a stainless steel extension part (Fig. 2). The column is filled to halfway in the extension part. The soil column was equilibrated with solution 1 (Table 2 ) that was pumped through the soil column with a velocity of $0.1 \mathrm{ml} \mathrm{min}{ }^{-1}$. Equilibration was reached after $20 \mathrm{~h}$. In that period the soil was completely saturated with calcium. The extension part was removed and the soil column closed. During preparation, the soil column was not connected to the outlet tube to the detector because some small particles may pass the filter in the column. These particles will then interfere with measurements in the detector. Manipulation with the extension part is necessary to make sure that the soil column is completely filled and no dead volumes are present (in the case that shrinking occurs) and not clogging up (in the case of swelling).

Table 1. Particle size distribution of the soil sample from the Nile delta in Egypt.

\begin{tabular}{lll}
\hline $\begin{array}{l}\text { Name of } \\
\text { fracton }\end{array}$ & $\begin{array}{l}\text { Particle size } \\
(\mu \mathrm{m})\end{array}$ & $\begin{array}{l}\text { Percentage in sample } \\
(\%)\end{array}$ \\
Sand & $>50$ & 7 \\
Silt & $2-50$ & 45.5 \\
Clay & $<2$ & 47.5 \\
\hline
\end{tabular}




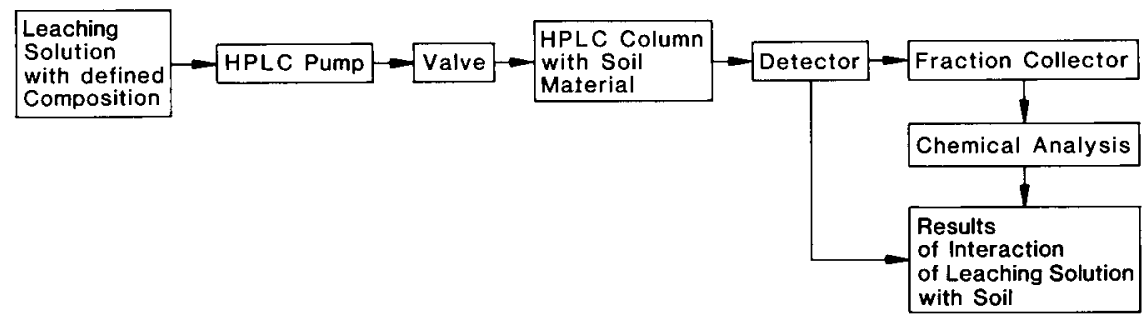

Fig. 1. Schematic illustration of column experiments.

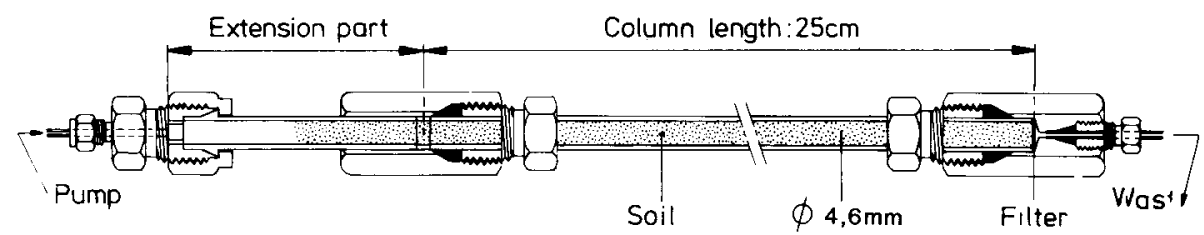

Fig. 2. The connection of the column with the extension part during the preparation of the column bed. The column outlet is not connected to the detector until the column is equilibrated after $20 \mathrm{~h}$.

Solutions 2 and 3 which have different ratios of $\mathrm{Na}: \mathrm{Ca}: \mathrm{Mg}$ (Table 2) were used for leaching. Between leaching with solution 2 and 3 a run was done with solution 1 . To be sure that equilibrium was reached after each solution, the column was leached overnight with the same solution after every experiment. Between the various experiments the soil was not allowed to dry and stayed saturated with water.

Before the start of any of the three runs the tubing in the HPLC pump (Varian LC 5000) and up to the soil column has to contain the proper solution. This can be accomplished by installing a three-way valve just before the column. The solution is first pumped through the tubing with the valve in a position that the solution is not directed through the column. When all tubing contains the right solution, an experiment started by changing the three-way valve such that solution is pumped through the soil column. The leaching effluent was collected using a fraction collector (Isco 1200 ) in a frequency of 1 sample every $20 \mathrm{~min}$ at a flow rate of $0.1 \mathrm{ml} \mathrm{min}^{-1}$.

Table 2. The composition of the leaching solutions. The $\mathrm{pH}$ was adjusted to 7.8 with a slurry of sodium hydroxide, calcium oxide and magnesium oxide in the same ratio as given for the solutions.

\begin{tabular}{lllllll}
\hline Solution & $\mathrm{pH}$ & $\begin{array}{l}\text { Electric } \\
\text { conductivity } \\
25^{\circ} \mathrm{C}\end{array}$ & $\begin{array}{l}\mathrm{NaCl} \\
(\mathrm{mM})\end{array}$ & $\begin{array}{l}\mathrm{NaHCO}_{3} \\
(\mathrm{mM})\end{array}$ & $\begin{array}{l}\mathrm{MgSO}_{4} \\
(\mathrm{mM})\end{array}$ & $\begin{array}{l}\mathrm{CaCl}_{2} \\
(\mathrm{mM})\end{array}$ \\
1 & 7.8 & 6.2 & 0 & & & \\
2 & 7.8 & 6.4 & 45 & 5 & 0 & 32.5 \\
3 & 7.8 & 5.8 & 30 & 5 & 2.5 & 5 \\
\hline
\end{tabular}


Total inorganic carbon of fractions and leaching influent was measured with the carbon analyser 915A of Beckman (Harmsen et al., 1979). Then the solutions were diluted 10 times and $\mathrm{Na}, \mathrm{Ca}$ and $\mathrm{Mg}$ were measured with an inductively coupled plasma emission spectrophotometer' (ICP) (IL 200 of Instrumentation Laboratory). Sulfate was measured with the turbidimetric method described in the 'Standard methods' (Anon., 1976). Because the sample was small, $5 \%$ of the recommended amounts were used.

The effective water volume $V_{0}$ can be measured with the breakthrough curve of a non-retarded component. We used nitrate because it is normally not adsorbed by the soil. Only in soils of vulcanic origin notable adsorption may occur (Kinjo et al., 1971). Under the experimental conditions realized a non-vulcanic soil was used. Adsorption of nitrate $\left(0.03 \mathrm{mmol}^{-1}\right)$ is also prevented by the high concentration of chloride $\left(65 \mathrm{mmol}^{-1}\right)$. Nitrate is also not affected by biological processes under the prevailing aerobical conditions and within the residence time of about $20 \mathrm{~min}$. Nitrate is preferred to chloride, which was often used (Hoeks \& Borst, 1982), because it can be measured continuously by UV spectrophotometry. $V_{0}$ was measured by adding $0.2 \mathrm{ml}$ of a solution containing $10 \mathrm{~g} \mathrm{l}^{-1}$ nitrate to a litre of influent solution with the column connected to an UV detector (Varichrom, Varian) measuring at a wavelength of $210 \mathrm{~nm}$.

\section{Modelling}

As described in 'Introduction', the present experiments were done to check a model on exchange/transport processes of cations in a homogeneous soil using a certain quality of irrigation water. The model used was developed by Groenendijk (internal report, 1985) with the following approach.

In the model two processes are taken into consideration:

- transport process: convective and dispersive flow of water and solutes;

- chemical process: chemical bonding of cation at an exchange complex.

Transport can be described by the 'mixing cell' concept. The 'mixing cell' concept, presented earlier by Goudriaan (1973) and van Ommen (1985) is the explicit backward numerical solution of the well-known Fokker-Planck equation, which can be held valid for the one-dimensional transport of solutes in a porous medium.

In this concept, a soil column is schematized in a number of homogeneous layers. The figures of the layer number (-), the linear velocity $\left(\mathrm{m} \mathrm{s}^{-1}\right)$ and the pore volume $(-)$ can be derived from the breakthrough curve of a conservative solute, using the theory of systems analysis (Roest, 1986).

The cation exchange is assumed at the end of each time interval, prescribed by the transport model, as a momentaneous reaction and is calculated for each soil layer. The ternairy exchange system has been approached by two exchange isotherms, a 'Gapon' and a 'Kerr' type of equation (Bolt \& Bruggenwert, 1978), and a charge balance of the cations considered:

$$
\text { Gapon: } K_{\mathrm{G}}=\frac{T_{\mathrm{Na}^{+}}}{T_{\mathrm{Ca}^{++}}} \times \frac{\sqrt{\left[\mathrm{Ca}^{++}\right]}}{\left[\mathrm{Na}^{+}\right]}
$$


Kerr: $\quad K_{\mathrm{K}}=\frac{T_{\mathrm{Ca}^{++}}}{T_{\mathrm{Mg}^{++}}} \times \frac{\left[\mathrm{Mg}^{++}\right]}{\left[\mathrm{Ca}^{++}\right]}$

Charge balance: $\Delta\left[\mathrm{Na}^{+}\right]+2 \Delta\left[\mathrm{Ca}^{++}\right]+2 \Delta\left[\mathrm{Mg}^{++}\right]=0$

where:

$K_{\mathrm{K}}=$ Kerr selectivity constant (-),

$K_{\mathrm{G}}=$ Gapon selectivity constant $\left(\mathrm{mol}^{-1 / 2} \mathrm{l}^{-1 / 2}\right)$,

$\left[\mathrm{Na}^{+}\right],\left[\mathrm{Ca}^{++}\right],\left[\mathrm{Mg}^{++}\right]=$concentration of sodium, calcium, and magnesium (mol $\left.1^{-1}\right)$,

$T_{\mathrm{Na}}, T_{\mathrm{Ca}}, T_{\mathrm{Mg}}=$ adsorbed quantity of sodium, calcium, and magnesium $\left(10^{-2} \mathrm{~mol}(\mathrm{e})\right.$ $\mathrm{kg}^{-1}$ ).

The correction factors for activities and presence of complexes are calculated from the Debije-Hückel equation and formation constants of the complexes. The factors are taken constant during the time of the experiment. The Gapon coefficient used was calculated from the equilibrium situation at the end of the experiment (Tables 2 and 3). The values obtained for solutions 1 and 2 were 0.60 and 0.65 , respectively. Bolt \& Bruggenwert (1978) have given a value of 0.5 based on activities, which corresponds with a value of 0.6 on basis of the concentrations used. A Gapon coefficient of 0.6 is used in the calculations. The Kerr coefficient could not be calculated from an equilibrium situation, because this was not achieved. Therefore the value was calculated from experimental results given by Assaad et al. (1981) with a magnesium occupation on the complex of about $20 \%$ resulting in a Kerr coefficient of 1.1. A simplified form of the model is presented in Fig. 3.

\section{Results and discussion}

\section{Breakthrough of nitrate}

Nitrate was used to establish the effective volume of water in the column, $V_{0}$. Fig. 4 shows the breakthrough of a nitrate solution. The area above this curve gives the breakthrough volume, which is equivalent to the effective water volume of the column $(1.65 \mathrm{ml})$. Data for the exchange/transport model are calculated from the curve input ignoring the tailing of the curve, i.e. the slow increase of $c / c_{0}$ to 1 . Therefore the calculated exchange curves are without tailing. A layer-thickness of $31 \mathrm{~mm}$ was calculated and 8 layers were used in the model.

The asymmetrical form of the breakthrough curve is also found when large diameter columns are used (Wieringa, 1977; Hoeks \& Borst, 1982). In the present small column the tailing can also be the result of the boundary effect (velocity at the wall surface is high compared to the velocity in the centre of the column). Tailing would then increase at higher leaching velocities. At velocities ranging from 0.02 to $0.2 \mathrm{ml}$ $\mathrm{min}^{-1}$, however, identical breakthrough curves were found, indicating that the present tailing is not a boundary effect. Although dispersion is velocity-dependent, the results indicate that this effect in the range of velocities used is within the experimental error. We assume that the effect is comparable to the effect in larger col- 


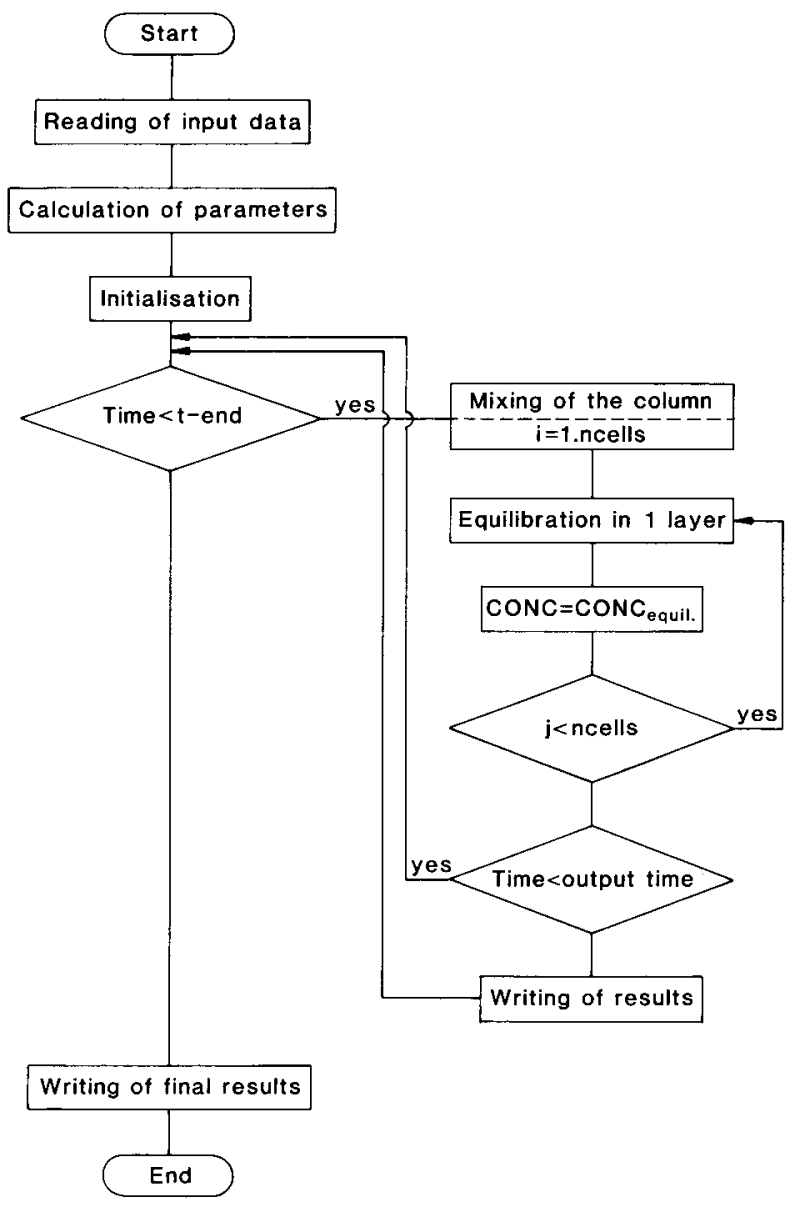

Fig. 3. Flowchart of the transport model SODIC (mixing cell concept exchange model) according to Groenendijk (internal report, 1985).

umns that is caused by a non-ideal particle and pore size distribution. A part of the solute can have permanently a lower flow velocity and therefore the micro velocity distribution will deviate from the Gauss distribution. The breakthrough curve will show an asymmetric behaviour and reach slowly the final concentration.

\section{Behaviour of anions}

The concentration of the ions in the effluent solutions was calculated relative to that of the influent solutions. When leaching with solution 1 , concentrations are relative to solution 2 , because solution 1 does not contain sulfate, inorganic carbon, sodium and magnesium. Chloride was not measured because it is not retarded by the soil. 


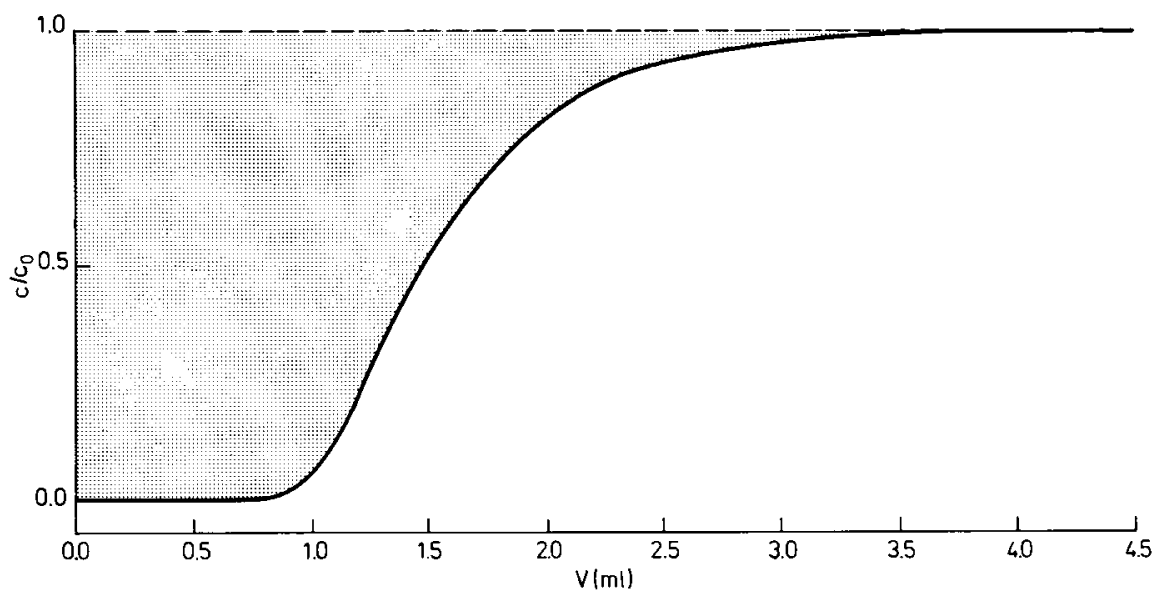

Fig. 4. Determination of $V_{0}$ as the surface area of the stippled part in the breakthrough curve of a nitrate solution. The quotient of the measured effluent and influent concentrations $\left(c / c_{0}\right)$ is plotted against volume (V).

Sulfate and inorganic carbon were measured because they may interact with the soil thereby influencing the concentrations of calcium and magnesium.

Fig. 5a,b shows that the sulfate curve almost fits with the nitrate curve. This means that sulfate has almost no interaction with the soil. The difference between nitrate and sulfate cannot be explained by precipitation, because the solubility of $\mathrm{CaSO}_{4}$ is not exceeded. Some interaction with the soil colloids may be present because these also have positive sites.

Inorganic carbon shows a different behaviour (Fig. 5a,b,c). The breakthrough is at 2 times $V_{0}$ and it does not reach equilibrium. This may be explained by the $\mathrm{pH}$ of the effluent. In the first part of the curve of Experiments a and b, the pH drops. The average $\mathrm{pH}$ in the first 5 fractions was 5.5, which results in an escape of $\mathrm{CO}_{2}$ when water leaves the column and the inorganic carbon concentration measured is too low. No explanation is found for the $\mathrm{pH}$ drop. After 5 fractions the effluent $\mathrm{pH}$ equals the influent $\mathrm{pH}$. At the end of the experiment the $\mathrm{pH}$ was even high enough to cause precipitation ( $\mathrm{pH} 8.3$ ). Calculations taking into account activities and ion pairs (Abdel Khalik \& Blömer, 1984) and the solubility product of ikaite $\mathrm{CaCO}_{3}$. $1 \mathrm{H}_{2} \mathrm{O}, \mathrm{pK}=7.9$ (Suarez, 1979; Bresler et al., 1982) demonstrate that the solubility product of calcium carbonate is exceeded.

Fig. 5c shows that the precipitated calcium carbonate present in the soil sample slowly dissolves because the effluent contains inorganic carbon while the leaching influent does not. During the time of this experiment, an equilibrium was not reached. It is also possible that the inorganic carbon enters the samples from the atmosphere, because the sampling occurs in an open system. Entrance of carbon dioxide will drop the $\mathrm{pH}$ of the effluent, which could not be established, because it was not possible to sample for and measure the $\mathrm{pH}$ of the effluent without contact with air. 


\section{S. EL GUINDY AND J. HARMSEN}
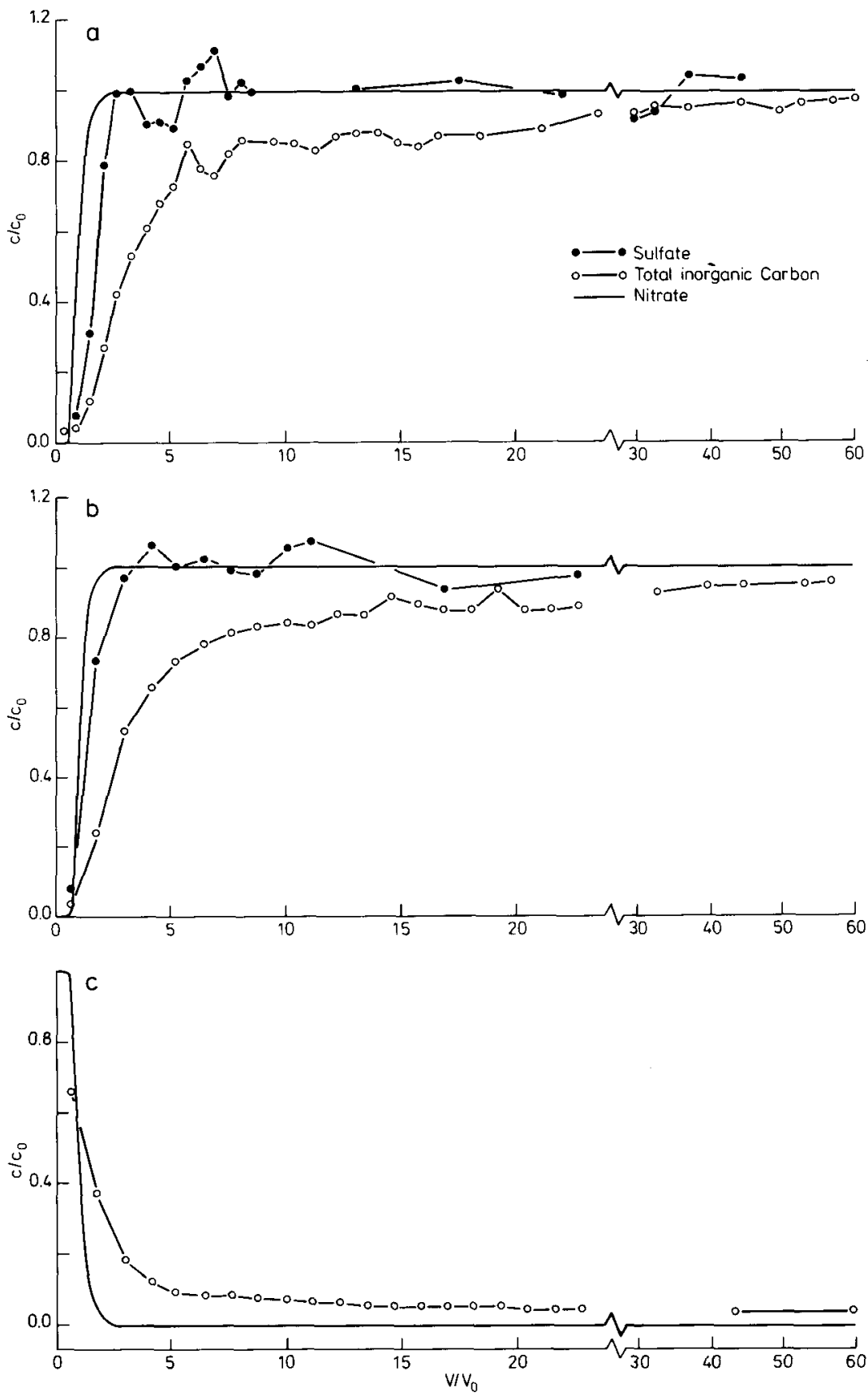

Fig. 5. Breakthrough curves of sulfate and inorganic carbon compared to the curve for nitrate. (a) solution $2,(b)$ solution $3,(c)$, solution 1 , after reaching equilibrium with solution 2 . 
The difference in inorganic carbon in influent and effluent in every second part of the curves presented in Fig. 5 is about $0.25 \mathrm{mmol}^{-1}$. If the inorganic carbon originates from calcium carbonate present in the soil sample, this should also result in a difference of the measured calcium concentration of $0.25 \mathrm{mmol} \mathrm{l}^{-1}$ compared with the influent concentration. For solution 1 and 3 this is negligible (i.e. the error in the measurements is more than $0.25 \mathrm{mmol} \mathrm{l}^{-1}$ ). No difference in Ca concentration was measured in solution 2. We assume that also in this part of the curve the measured inorganic carbon concentrations may be influenced by the problems in sampling of inorganic carbon mentioned before. Only an online method for measurement of $\mathrm{pH}$ and inorganic carbon without air contact would have provided unequivocal information.

\section{Behaviour of cations}

For the exchange of cations, diffusion to exchange places can be a limiting factor. We tested this in an experiment with the normal flow rate $\left(0.1 \mathrm{ml} \mathrm{min}^{-1}\right)$ and with a reduced flow rate $\left(0.025 \mathrm{ml} \mathrm{min}{ }^{-1}\right)$. The sodium and magnesium breakthrough curves were identical (Fig. 6), showing that the different velocities had no influence on the exchange process and that time dependency is no problem in this case.

The present type of experiments may, however, be influenced by other time-dependent processes. This was found with a Dutch sandy soil when working at a lower $\mathrm{pH}$. This causes dissolution of calcium carbonate, a time-dependent process that influences the results, especially at low calcium concentrations in the influent. Time dependency may be a problem with other soil types (James \& Rubin, 1979) and has to be checked.

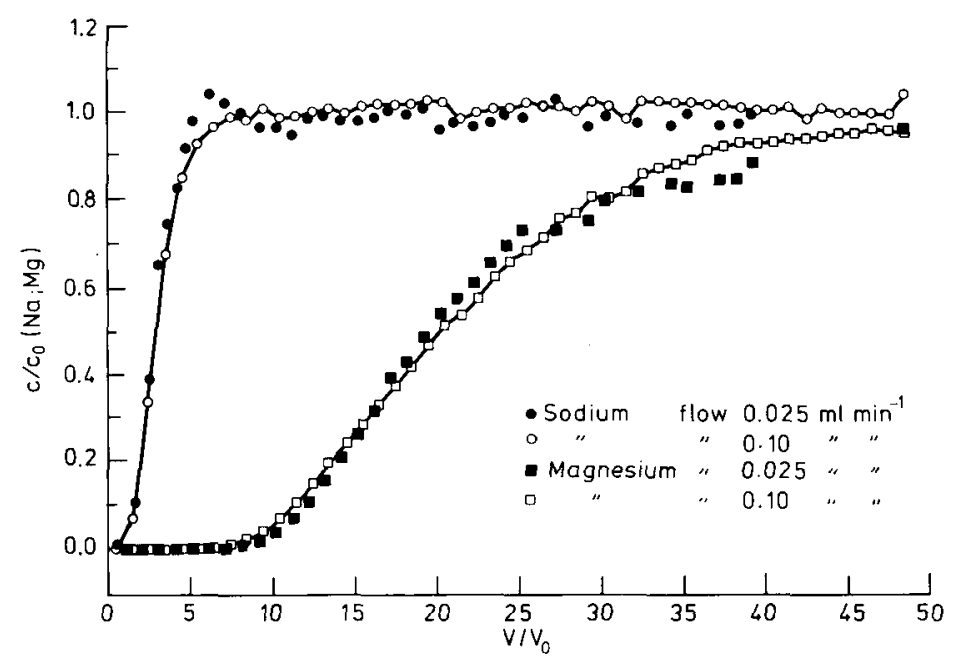

Fig. 6. Breakthrough of sodium and magnesium at two different flow rates. The slopes in this figure differ from the slopes in Fig. $7 \mathrm{~b}$ because differently packed soil columns were used. 


\section{S. EL GUINDY AND J. HARMSEN}
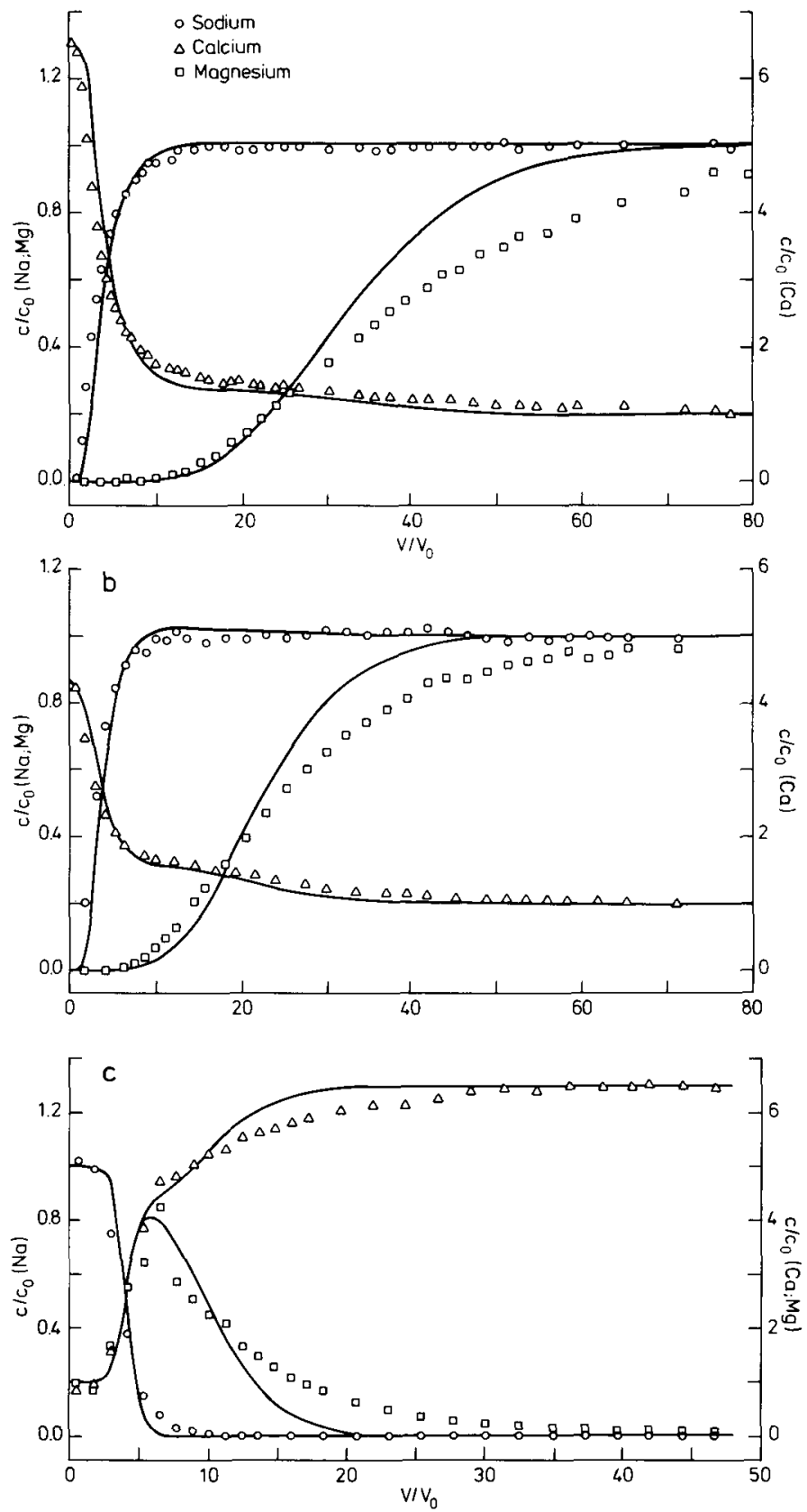

Fig. 7. Breakthrough of sodium, magnesium and calcium. The lines represent the calculted breakthrough curves, whereas the symbols mark the measured values. $(a)$ solution $2,(b)$ solution $3,(c)$ solution 1, after reaching equilibrium with solution 2 . 
The measured breakthrough curves of cations are presented in Fig. 7, together with the calculated ones. The breakthrough curves demonstrate that calcium and sodium interchange quickly. After 10 times $V_{0}$ sodium already reaches an equilibrium. The calculated curve is similar to the measured curve, which indicates that the assumptions in the model are correct for this exchange. The calculated curve for sodium exceeds the relative concentration of 1 (Fig. 7b). This occurs on the moment that the breakthrough of magnesium starts and magnesium displaces part of the already adsorbed sodium. This effect, however, is within the error of the experimental curve and could not be established with the experiment.

Replacement of calcium by magnesium or magnesium by calcium, on the other hand, occurs at higher $V / V_{0}$, especially in solution 2 where the ratio $\mathrm{Mg} / \mathrm{Ca}$ was lower than in solution 3. In this case the first part of the curve can be described with the Kerr coefficient of 1.1. The slope especially of the second part of the calculated curve does not completely fit the experimental curve (Fig. 7). This cannot be explained by the fact that tailing is ignored in the model (cf. Fig. 4). This would also have caused deviation in the breakthrough curve of the other cations.

The deviation can be explained by the fact that a constant Kerr coefficient is used in the model. This coefficient is, however, changing with the occupation of the cation complex (Bolt, 1982) reducing the slope of the experimental curve. Also the Kerr coefficients calculated from the results of Assaad et al. (1981) depend on the magnesium occupation. In soils with $10,40,60,80$ and $100 \%$ magnesium occupation the coefficients were respectively $0.97,1.34,1.40,1.85$ and 2.13 . When a more accurate model is needed it should be possible to work with a CEC divided into sites with different Kerr coefficients or with a Kerr coefficient that changes with the magnesium occupation.

From the measured values the total amount of exchanged sodium, magnesium and calcium ions can be calculated (Table 3). For solutions 2 and 3 the sum of the amount of exchanged sodium and magnesium ions is not equal to that of calcium. This is largely due to an inaccuracy in the results, because each value is the summation of about 60 small figures. The differences cannot be explained by precipitation of $\mathrm{CaCO}_{3}$, as this would even increase the imbalance. For solution 1 the balance is correct. The absolute amount of exchanged magnesium extracted with solution 1 is higher than the amount added with solution 2 . The reason for this difference is that solution 1 is not applied immediately after the experiment with solution 2 and because at the end of the experiment with solution 2 the relative concentration of

Table 3. Amount of exchanged cations during leaching with solution 1,2 and $3 .+=$ from water to soil, $-=$ from soil to water.

\begin{tabular}{llll}
\hline $\begin{array}{l}\text { Exchanged } \\
\text { ion }\end{array}$ & $\begin{array}{l}\text { Solution 2 } \\
\left(\text { mol }(\mathrm{e}) \mathrm{kg}^{-1}\right)\end{array}$ & $\begin{array}{l}\text { Solution } 3 \\
\left(\operatorname{mol}(\mathrm{e}) \mathrm{kg}^{-1}\right)\end{array}$ & $\begin{array}{l}\text { Solution 1 } \\
\left(\mathrm{mol}(\mathrm{e}) \mathrm{kg}^{-1}\right)\end{array}$ \\
$\mathrm{Na}^{+}$ & +0.122 & +0.071 & -0.130 \\
$\mathrm{Mg}^{2+}$ & +0.149 & +0.219 & -0.170 \\
$\mathrm{Ca}^{2+}$ & -0.287 & -0.307 & +0.303 \\
\hline
\end{tabular}


magnesium had not reached the value of 1 (Fig. 7). The soil column was leached another 16 hours (overnight) with solution 2, resulting in a higher magnesium level on the exchange complex.

\section{Conclusions}

The fast soil-column technique described in this paper has shown to be a promising tool in the research of transport of cations in a soil. It can be used instead of timeconsuming large column experiments for checking models describing the solution concentration as a function of depth in a soil column or leaching volume in case of the assumption of ion exchange. Such a model can be a part of a complicated solute transport model. The main advantage is that one soil column experiment can be done within one day.

The present technique cannot be used for testing the transport behaviour of inorganic carbon because the equilibrium present at the end of the column may change when the water leaves the column due to a different $\mathrm{CO}_{2}$ pressure inside and outside the column.

For the exchange of magnesium against calcium in the presently used soil a model describing transport and exchange with a constant exchange coefficient does not fit the experimental results completely. This may be improved by leaving the concept of a constant exchange coefficient. The model can be used for the sodium-calcium exchange.

\section{References}

Anon., 1976. Standard methods. Standards methods for examination of water and waste water. 14th edn. American Public Health Association, New York, 1193 pp.

Assaad, F. F., F. Awad \& S. Marei, 1981. A computer model for the prediction of Ca-Mg cations in a soil system in the presence of $\mathrm{CaCO}_{3}$. Egyptian Journal of Soil Science 21: 239-250.

Abdel Khalik, M. \& F. Blömer, 1984. COMPLEX, a computer model for solving chemical equilibria on the basis of activities. Report 2. Reuse of Drainage Water Project. Institute for Land and Water Management Research (ICW), Wageningen/Drainage Research Institute, Cairo, 31 pp.

Bolt, G. H., 1982. Soil chemistry. B. Physico-chemical models. Elsevier, Amsterdam, 527 pp.

Bolt, G. H. \& M. G. M. Bruggenwert, 1978. Soil chemistry. A. Basic elements. Elsevier, Amsterdam, $281 \mathrm{pp}$.

Bresler, E., B. L. McNeal \& D. L. Carter. 1982. Saline and sodic soils. Principles dynamic modelling. Springer Verlag, New York, $226 \mathrm{pp}$.

Goudriaan, J., 1973. Dispersion in simulation models of population growth and salt movement in the soil. Netherlands Journal of Agricultural Science 21: 269-281.

Harmsen, J., H. van Drumpt \& J. M. Muijlaert, 1979. A fast method for the determination of bicarbonate in soil surface and waste water. $\mathrm{H}_{2} \mathrm{O} 12: 585-586$.

Hoeks, J. \& R. J. Borst, 1982. Anaerobic digestion of free volatile fatty acids in soils below waste tips. Water, Air and Soil Pollution 17: 165-173.

James, R. V. \& J. Rubin, 1979. Applicability of the local equilibrium assumption to transport through soils of solutes affected by ion exchange. In: E. A. Jenne (Ed.), Chemical modelling in aqueous systems, p. 225-235. ACS Symposium, Series 93, American Chemical Society.

Kinjo, T. \& P. F. Pratt, 1971. Nitrate adsorption. I. In some acid soils of Mexico and South America. Soil Science Society of America Proceedings 35: 722-725. 


\section{RAPID SOIL COLUMN TECHNIQUE TO STUDY TRANSPORT OF CATIONS}

Ommen, H. C. van, 1985. The 'mixing-cell' concept applied to transport of non-reactive and reactive components in soils and groundwater. Journal of Hydrology 78: 201-213.

Roest, C. W. J., 1986. Trade a simple water quality model for transport, adsorption and decomposition of solutes in the soil. Proceedings International Conference 'Water Quality Modelling in the Inland Natural Environment', Bournemouth (UK), p. 93-103.

Suarez, D. L., 1977. Ion activity product in the root zone. Soil Science Society of America Journal 41: 310-315.

Wieringa, P. J., 1977. Solute distribution profiles computed with steady-state and transient water movement models. Soil Science Society of America Journal 41: 1050-1055. 